\title{
The Cognitive Walkthough for Implementation Strategies (CWIS): A Pragmatic Method for Assessing Implementation Strategy Usability
}

\author{
Aaron R Lyon ( $\sim$ lyona@uw.edu ) \\ University of Washington https://orcid.org/0000-0003-3657-5060 \\ Jessica Coifman \\ University of Washington \\ Heather Cook \\ University of Washington
}

Erin McRee

University of Washington

Freda F. Liu

University of Washington

Kristy Ludwig

University of Washington

Shannon Dorsey

University of Washington

Kelly Koerner

Evidence-Based Practice Institute, Inc.

\section{Sean A. Munson}

University of Washington

Elizabeth McCauley

University of Washington

\section{Methodology}

Keywords: Implementation strategies, human-centered design, usability, cognitive walkthrough

Posted Date: December 30th, 2020

DOI: https://doi.org/10.21203/rs.3.rs-136222/v1

License: (c) (1) This work is licensed under a Creative Commons Attribution 4.0 International License. Read Full License 
Version of Record: A version of this preprint was published at Implementation Science Communications on July 17th, 2021. See the published version at https://doi.org/10.1186/s43058-021-00183-0. 


\section{Abstract}

Background. Implementation strategies have flourished over the last decade in an effort to increase integration of research evidence into clinical practice. Most strategies are complex, socially-mediated processes. Many are complicated, expensive, and ultimately impractical to deliver in real-world settings. The field lacks methods to assess the extent to which implementation strategies are usable and aligned with the needs and constraints of the individuals and contexts who will deliver or receive them. Drawn from the field of human-centered design, cognitive walkthroughs are an efficient assessment method with potential to surface aspects of strategies that may inhibit their usability and, ultimately, their effectiveness. This article presents a novel cognitive walkthrough methodology for evaluating strategy usability as well as an example application to a post-training consultation strategy to support mental health clinicians in the education sector to adopt measurement-based care.

Method. The Cognitive Walkthrough for Implementation Strategies (CWIS) is a pragmatic, mixed-methods approach for evaluating complex, socially-mediated implementation strategies in health. CWIS includes six steps: (1) determine preconditions; (2) hierarchical task analysis; (3) task prioritization; (4) convert tasks to scenarios; (5) pragmatic group testing; and (6) usability issue identification, classification, and prioritization. A facilitator conducted two group testing sessions with clinician users $(N=10)$, guiding participants through 6 scenarios and 11 associated subtasks. Clinicians reported their anticipated likelihood of completing each subtask and provided qualitative justifications during group discussion. Following the walkthrough sessions, users completed a quantitative assessment of strategy usability.

Results. Average subtask success ratings indicated substantial variability across participants and subtasks. Usability ratings (scale: $0-100)$ of the consultation protocol averaged $71.3(S D=10.6)$. Twenty-one usability problems were identified via qualitative coding and classified by severity and problem type to explain the ratings. High-severity problems included potential misalignment between consultation and clinical service timelines as well as digressions during consultation processes.

Conclusions. Ratings indicated that usability of the consultation protocol was at the low end of the "acceptable" range. Collectively, the 21 usability issues explained the ISUS quantitative usability data and provided specific direction for usability enhancements. The current study provides preliminary evidence for the utility of CWIS to assess strategy usability and generate a blueprint for redesign.

\section{Contributions To The Literature}

- Implementation strategies are increasingly complex, but the field lacks methods to assess the extent to which implementation strategies are usable and aligned with the needs and constraints of the individuals and contexts who will deliver or receive them.

- The Cognitive Walkthrough for Implementation Strategies (CWIS) is a novel method for assessing strategy usability, filling a critical gap in the implementation literature and informing implementation strategy tailoring, adaptation, and redesign processes. 
- Findings from the current application indicate that CWIS has utility for identifying implementation strategy usability problems and informing contextually-appropriate strategy redesign.

\section{Background}

The past two decades have brought growing realization that research evidence - often codified in evidencebased practices (EBPs) - is used infrequently, inconsistently, or inadequately in standard clinical care across numerous domains [1, 2]. As a result, considerable effort has been devoted to developing implementation strategies to explicitly address the gaps between research and practice. Implementation strategies are methods or techniques used to enhance the adoption, implementation, and sustainment of new practices and may be discrete (i.e., involving single actions or processes such as reminder systems) or multifaceted (i.e., combining two or more discrete strategies) [3]. These strategies are now rapidly proliferating, with multiple compilations identified across a variety of health service delivery sectors $[4,5]$.

The complexity of implementation strategies varies widely, but most strategies are socially-mediated processes that rely, in large part, on interactions among practitioners, implementation intermediaries/practitioners, or researchers [6]. Multifaceted and multi-level strategies are increasingly common, some of which are intended to be delivered over one or more years [7-9]. Growing implementation strategy complexity has been fueled, in part, by the pursuit of larger effect sizes and findings that multicomponent and multi-level strategies may be more effective in promoting positive implementation outcomes $[10,11]$. Simultaneously, significant complexity leaves many implementation strategies unwieldy, expensive, and ultimately impractical to deliver in real-world community contexts due to excessive burden and potential lack of alignment with the needs of end users. Although the selection and tailoring of implementation strategies to meet contextual determinants has emerged as a major focus of contemporary implementation research $[7,12,13]$, we lack methods to assess the extent to which implementation strategies are usable and aligned with the specific needs and constraints of the individuals who will use them. To be maximally relevant and useful, it is important to ensure that such methods are pragmatic [14, 15]; meaning that they should be efficient and low burden, feasible to conduct in real-world settings, and yield actionable information that directly informs decisions about implementation strategy design.

\section{Human-centered Design (hcd)}

Methods drawn from the field of human-centered design (HCD; closely related to user-centered design) can be adapted to assess implementation strategy usability and ensure contextual fit in ways that meet pragmatic criteria. HCD is focused on developing compelling and intuitive products, grounded in knowledge about the people and contexts where an innovation will ultimately be deployed [16, 17]. HCD is aligned with the growing emphasis on "design thinking" in healthcare surrounding digital devices, electronic health records, and patient experience [18]. Although little work has applied HCD specifically to implementation strategies, an emerging literature has begun to discuss the potential of HCD methods and processes for strategy development and redesign. For instance, both the Discover, Design/Build, Test (DDBT) framework [4] and the Accelerated Creation to Sustainment (ACTS) framework [19] leverage HCD processes for the 
contextually-appropriate redesign of evidence-based interventions as well as implementation strategies for healthcare. Nevertheless, despite the value of these overarching frameworks, specific methods are needed surrounding the types and ways that data that should be collected and synthesized in service of implementation strategy development and adaptation goals.

Usability, the extent to which a product can be used by specified individuals to achieve specified goals in a specified context [20], is a key outcome of HCD processes. Usability is also a critical factor driving the adoption and delivery of new innovations, including implementation strategies [21-23]. The construct of usability can be distinguished from implementation constructs such as acceptability, feasibility, and appropriateness. Usability is largely a characteristic of an innovation (e.g., a complex implementation strategy) and a determinant - rather than an outcome - of its successful use [24]. A major advantage of $\mathrm{HCD}$ is that it emphasizes rapid and efficient information collection to assess the degree to which a product is compelling and usable. A second advantage is to identify usability problems, or aspects of an innovation and/or a demand on the user which make it unpleasant, inefficient, onerous, or impossible for the user to achieve their goals in typical usage situations [25]. Existing methods such as concept mapping, group model building, conjoint analysis, and intervention mapping have great potential for strategy tailoring [7], but do not address the core issue of strategy usability.

\section{Cognitive Walkthroughs}

Cognitive walkthroughs are a low-cost assessment method commonly used in HCD usability evaluations, with the potential to surface aspects of complex implementation strategies that may inhibit their use (and ultimately their effectiveness) in community contexts. Most typically, cognitive walkthroughs are designed to simulate the cognitive behavior of users by specifically asking questions related to users' internal cognitive models and expectations for particular scenarios and tasks [26]. The method is particularly applicable when the goal is to determine the extent to which products support "first time use" (i.e., use without prior or significant exposure to a specific product, interface, or protocol) [27]. Many variants exist [28], and walkthroughs may be conducted either one-on-one or in a group format. Relative to individual methods, group walkthrough procedures may minimize associated costs and capitalize on opportunities for interactions among users, thus enhancing the depth and quality of the resulting data [29]. Despite their near ubiquity in much of the HCD literature, cognitive walk-throughs have rarely been applied in the context of implementation studies, and never to the evaluation of implementation strategies themselves.

\section{Current Aims}

This article presents a novel, pragmatic cognitive walkthrough methodology for evaluating implementation strategy usability by identifying, organizing, and prioritizing usability issues. We also describe an example application of the walkthrough methodology to a post-training consultation strategy for child and adolescent mental health clinicians working in the education sector, who had recently completed training in measurement-based care. Schools have long been the most common setting in which children and adolescents receive mental health services in the United States [30, 31]. Measurement-based care (MBC) - 
the systematic collection and use of patient symptom and functioning data to drive clinical decision making [32]- is a well-supported practice for improving mental healthcare delivery [33, 34]. MBC is well aligned with the school setting, but inconsistently applied by school-based mental health clinicians, necessitating targeted and contextually appropriate implementation strategies $[35,36]$. Although the example used is specific to school-based mental health service delivery and focuses on clinicians (one primary user group for post-training consultation), the walkthrough method is designed to be generalizable across settings, users, and implementation strategies. The methodology is intended for application by implementation researchers or practitioners who seek to ensure that the strategies they employ are easy to use and useful for relevant stakeholders.

\section{Methodology And Case Study Application}

\section{Cognitive Walkthrough for Implementation Strategies (CWIS) Overview}

The Cognitive Walkthrough for Implementation Strategies (CWIS; say "swiss") is a streamlined walkthrough method adapted to evaluate complex, socially-mediated implementation strategies in healthcare. As described below, CWIS is pragmatic [37] and uses a group-based data collection format to maximize the efficiency of information gathering. Importantly, CWIS differs from standardized patient walkthroughs, which are used to evaluate research study procedures - such as consent or screening [38] - or to assess the degree to which existing clinical services or health systems are responsive to patient needs [39]. Such approaches do not provide clear methods for specifying and prioritizing areas for implementation strategy redesign. As described below, the CWIS methodology includes six steps: (1) determine preconditions; (2) hierarchical task analysis; (3) task prioritization; (4) convert tasks to scenarios; (5) pragmatic group testing; and (6) usability issue identification, classification, and prioritization (see Figure 1).

Example application: Post-training consultation. Below, our descriptions of the CWIS steps are followed by a brief application to a commonly-used implementation strategy: post-training, expert consultation for clinicians. Consultation involves ongoing support from one or more experts in the innovation being implemented and the implementation process $[5,40]$. Given that studies consistently document that initial training alone is insufficient to effect changes in professional behavior $[10,41,42]$, post-consultation has become a cornerstone implementation strategy for supporting the adoption and use of EBPs in mental health $[43,44]$. In our example, CWIS was used to evaluate a brief (2-8 week) consultation strategy intended for school clinicians who had recently completed a self-paced online training in MBC. The consultation strategy included (1) weekly use of an asynchronous message board to further support knowledge gains and accountability, as well as (2) live, biweekly group calls to discuss cases, solidify skills, and support the application of MBC practices with clinician caseloads.

\section{Step 1: Determine Preconditions for the Implementation Strategy}

Preconditions reflect the situations under which an implementation strategy is likely to be indicated or effective [45]. In CWIS, articulation of preconditions (e.g., characteristics of the appropriate initiatives, settings, individuals, etc.) is necessary to ensure a valid usability test of the target implementation strategy. Explicit identification of end users is a key aspect of precondition articulation and hallmark of HCD 
processes [46]. Studies indicate that, in the absence of explicit user identification processes, product developers tend to underestimate user diversity and, consequently, base designs on individuals like themselves [47,48]. In CWIS, if preconditions for implementation strategies are not met, the scenarios or users with which the strategy may be applied in subsequent steps will be non-representative of its intended application. For instance, the strategy, "change accreditation or membership requirements" [5] may require as a precondition clinicians or organizations who are active members of relevant professional guilds.

Example application. When applied to post-training consultation for MBC in the current project, the research team identified individual-level preconditions that made clinicians appropriate candidates to receive the consultation strategy. These included that clinicians provided mental health services in the education sector for some or all of their professional deployment; had expressed (by way of their participation) an interest in adopting MBC practices; and had previously completed the online, self-paced training in MBC practices that the consultation model was designed to support. Detailed personas (i.e., research-based profiles of hypothetical users and use case situations; [49] were developed to reflect identified target users.

\section{Step 2: Hierarchical Implementation Strategy Task Analysis}

Hierarchical task analysis includes identifying all tasks and subtasks that have independent meaning and collectively compose the implementation strategy [50]. Tasks may be behavioral/physical (e.g., taking notes; speaking) or cognitive (e.g., prioritizing cases) [51,52]. Cognitive tasks are groups of related mental activities directed toward a goal [53]. These activities are often unobservable, but are frequently relevant to the decision making and problem-solving activities that are central to many implementation strategies. In CWIS, tasks, subtasks, and task sequences (including those that are behavioral and/or cognitive) are articulated by individuals with knowledge of the strategy by asking a series of questions: First, for each articulated larger task or task category, asking "how?" can facilitate the identification of subtasks. Second, asking "why?" for each task surfaces information about how activities fit into a wider context or grouping. Third, asking "what happens before?" and/or "what happens after?" can allow aspects of task temporality and sequencing to emerge. All tasks identified in Step 2 can be represented either as a table or as a flow chart.

Example application. Tasks reflected in the existing MBC consultation model and tested in the CWIS study were originally informed by the core consultation functions articulated by Nadeem, Gleacher, and Beidas [40] (including continued training, problem-solving, engagement, case applications, accountability, adaptation, mastery skill building, and sustainment planning). Members of the project team with expertise in clinical consultation procedures identified the tasks and subtasks in the consultation model via an iterative and consensus-driven process that involved task generation, review, and revision. In this process, a task analysis of the protocol was completed using the three questions described above. Tasks were placed in three categories, depending on whether they related to live consultation calls, interactions with the asynchronous message board, or work required between consultation sessions. A list of hierarchically-organized tasks was distributed to the rest of the developers of the consultation protocol for review and feedback. The first author then revised the task list and distributed it a second time to confirm that all relevant tasks had been identified. A number of tasks were added or combined through this process to produce the final set of 24 unique tasks for further review and prioritization in Step 3 (see Table 1). 


\section{Step 3: Task Prioritization Ratings}

Owing to their complexity, it is rarely feasible to conduct a usability evaluation that includes the full range of tasks contained within an implementation strategy. In CWIS, tasks are prioritized for testing based on (1) the anticipated likelihood that users might encounter issues or errors when completing a task, and (2) the criticality or importance of completing the task correctly. Likert-style ratings for each of these two dimensions are collected, ranging from " 1 " (unlikely to make errors/unimportant) to " 5 " (extremely likely to make errors/extremely important). These ratings should be completed by individuals who have expertise in the implementation strategy, the context or population with which it will be applied, or both. Tasks are then selected and prioritized based on both of these ratings simultaneously.

Example application. Tasks identified in Step 2 were reviewed and rated by four members of the research team with extensive experience in post-training consultation and MBC practices. Mean importance/criticality and error likelihood ratings were calculated across respondents (Table 1). Across tasks, the two ratings were correlated at $r=0.71$. Top-rated tasks (i.e., those with high ratings on both importance and error likelihood) were selected for testing and used to drive scenario development (see below). One highly-rated task ("Log into message board") was deprioritized since it was a fully digital process and could be readily addressed in a more traditional usability evaluation, rather than one with more complex behavioral or cognitive components. In all, Step 3 resulted in five consultation tasks being identified for testing in the CWIS process.

\section{Step 4: Convert Top Tasks to Testing Scenarios}

Task-based, scenario-driven usability evaluations are a hallmark of HCD processes. Once the top tasks (approximately 4-6) have been identified, they need to be represented in an accessible format for presentation and testing in cognitive walkthroughs. In CWIS, tasks from Step 3 are used to develop overarching scenarios that provide important background information and contextualize the tasks. Scenarios are generally role-specific, so the target of an implementation strategy (e.g., clinicians) might be presented with a different set of scenarios and tasks than the deliverer of an implementation strategy (e.g., expert consultants). CWIS scenarios provide contextual background information on timing (e.g., "it is the first meeting of the implementation team"), information available (e.g., "you have been told by your organization that you should begin using [EBP]"), or objectives (e.g., "you are attempting to modify your clinical practice to incorporate a new and innovative practice"). Tasks are sometimes expanded or divided into more discrete subtasks at this stage. Some scenarios might contain a single subtask while other scenarios might have multiple subtasks. Regardless, each scenario presented in CWIS should include the following components to ensure clear communication to participants: (1) a brief written description of the scenario and subtasks, (2) a script for a facilitator to use when introducing each subtask, and (3) an image or visual cue that represents the scenario and can be used to quickly communicate the subtasks' intent.

Example application. Based on the prioritized tasks, the research team generated six scenarios for CWIS testing. These scenarios reflected common situations that users would be likely to encounter when participating in consultation. Each scenario contained 1-3 specific subtasks. Figure 2 displays an example scenario and its subtasks whereas Additional File 1 contains all scenarios and subtasks used in the application of CWIS to MBC consultation procedures. 


\section{Step 5: Group Testing with Representative Users}

In Step 5, the testing scenario materials developed in Step 4 are presented to small groups of individuals (i.e., 4-6) who represent target users of the implementation strategy. User characteristics identified in Step 1 (Determine Preconditions) should guide the recruitment of users who reflect primary user groups, or the core individuals who are expected to use a strategy or product [46,54]. The primary users of implementation strategies often include both the targets of those strategies as well as the implementation practitioners who deliver them. For instance, testing components of a leadership-focused implementation strategy (e.g., Leadership and Organizational Change for Implementation; [55]) could include representative leaders from the organizations in which the strategy is likely to be applied as well as leadership coaches from the implementation team. If a broader strategy (e.g., change record systems; [5]) is selected for testing, then multiple groups reflecting different user types may need to be recruited (e.g., clinicians, supervisors, patients). Regardless, it is advantageous to construct testing groups that reflect single user types to allow for targeted understanding of their needs. In addition to primary users, secondary users (i.e., individuals whose needs may be accommodated as long as they do not interfere with strategy's ability to meet the needs of primary users) may also be specified.

CWIS sessions are led by a facilitator and involve presentation of a scenario/subtask, quantitative ratings, and open-ended discussion, with notes taken by a dedicated scribe. CWIS uses note takers instead of transcribed audio recordings to help ensure that it is pragmatic and efficient. First, each scenario is presented in turn to the group, followed by its specific subtasks. For each subtask, participants reflect on the activity, have an opportunity to ask clarifying questions, and then respond to three items about the extent to which they anticipate being able to (1) know what to do (i.e., discovering that the correct action is an option), (2) complete the subtask correctly (i.e., performing the correct action or response), and (3) learn that they have performed the task subtask correctly (i.e., receiving sufficient feedback to understand that they have performed the right action). They record these ratings using a 1-4 scale (1. a very small chance of success, 2. a small chance of success, 3 . a probable chance of success, or 4 . a very good chance of success) independently on a rating form (Additional File 2). Next, participants sequentially provide verbal justifications or "failure/success stories," which reveal the assumptions underlying their rating choices [28]. Any anticipated problems that arise are noted as well as any assumptions made by the participants surrounding the strategy, its objectives, or the sequence of activities. Finally, having heard each other's justifications for their ratings, the participants engage in additional open-ended discussion about the subtask and what might interfere with or facilitate its successful completion. During this discussion, note takers attend specifically to additional comments about usability issues for subsequent classification and prioritization in Step 6.

At the conclusion of a CWIS session, participants complete a quantitative measure designed to assess the overall usability of the implementation strategy. A wide variety of quantitative measures exist to identify usability problems for digital products, but none have been designed for implementation strategies. For CWIS, our research team adapted the widely-used 10-item System Usability Scale [56,57] for use with implementation strategies. The resulting Implementation Strategy Usability Scale (ISUS; Additional File 3) is 
CWIS' default instrument for assessing overall usability and efficiently comparing usability across different strategies or iterations of the same strategy.

Example application. Potential primary users included both clinicians and MBC expert consultants, but only clinicians were selected for testing given the modest goals of the CWIS pilot and because the deliverers of the consultation protocol (i.e., expert consultants) were already directly involved in its development. CWIS participants $(n=10)$ were active mental health clinicians who primarily provided services in $\mathrm{K}-12$ education settings and had completed a self-paced, online training in MBC (see Step 1: Preconditions). Participating clinicians came from a variety of school districts and agencies, were $90 \%$ female, and had been in their roles for 2-18 years. Table 2 displays all participant demographics. Human subjects approval was obtained by the University of Washington Institutional Review Board and all participants completed standard consent processes.

A facilitator conducted two CWIS sessions (including 4 and 6 clinicians, respectively) and guided each group through the six scenarios and eleven associated subtasks (Additional File 1). As detailed above, users were asked to rate each task based on their personal anticipated likelihood of success discovering the correct action, likelihood of performing that action, and likelihood that they would know about the success or failure of their action. Average success ratings for each subtask were calculated as the mean of all questions and user ratings and incorporated into a matrix cross-walking the team's original importance ratings with the success ratings generated by users.

Next, clinicians provided open-ended rating justifications and engaged in additional group discussion, including describing why some subtasks were considered more difficult than others and what aspects of subtasks they found particularly confusing or difficult. Discussion was recorded by the note taker for subsequent synthesis by the research team. Following the walkthrough sessions, users completed the ISUS in reference to all aspects of the consultation protocol to which they had been exposed.

\section{Step 6: Usability Issue Identification, Prioritization, and Classification}

Within CWIS, usability issues are identified, classified, and prioritized using a structured method to ensure consistency across applications. All usability issues are identified based on the results of Step 5 testing.

Identification and prioritization. In CWIS, identification of usability issues occurs in accordance with recent guidance articulated by the University of Washington ALACRITY Center $[4,58]$ for articulating usability issues for complex psychosocial interventions and strategies. Specifically, usability issues should include (1) a brief description (i.e., a concise summary of the issue, focused on how the strategy fell short of meeting the user's needs and its consequences), (2) severity information (i.e., how problematic or dangerous the issue is likely to be on a scale ranging from 0 ["catastrophic or dangerous"] to 4 ["subtle problem"], adapted from Dumas and Redish [59]), (3) information about scope (i.e., the number of users and/or number of components affected by an issue), and (4) indicators of its level of complexity (i.e., how straightforward it is to address [low, medium, high]). The consequences of usability issues (a component of issue descriptions) may either be explicitly stated by participants or inferred during coding. Determinations about severity and scope are informed by the extent to which usability issues were known to impact participants' subtask 
success ratings (Step 5). Usability issues that are severe and broad in scope are typically the most important to address. Those that are also low in complexity may be able to be prioritized for the most immediate changes to the strategy because they may be the easiest to immediately improve [60].

Classification. In CWIS, all identified usability problems are classified by the research team using a consensus coding approach and a framework adapted from the enhanced cognitive walkthrough articulated by Bligård and Osvalder [28]. The first category includes issues associated with the user $(U)$, meaning that the problem is related to the experience or knowledge a user has been able to access (e.g., insufficient information to complete a task). Second, an implementation strategy usability problem may be due to information being hidden $(H)$ or insufficiently explicit about the availability of a function or its proper use. Third, issues can arise due to sequencing or timing (ST), which relates to when implementation strategy functions have to be performed in an unnatural sequence or at a discrete time that is problematic. Fourth, problems with strategy feedback $(F)$ are those where the strategy gives unclear indications about what a user is doing or needs to do. Finally, cognitive or social (CS) issues are due to excessive demands placed on a user's cognitive resources or social interactions. Usability issue classification is critical because it facilitates aggregation of data across projects and allows for more direct links between usability problems and potential implementation strategy redesign solutions. For instance, user issues may necessitate reconsideration of the target users or preconditions (e.g., amount of training/experience) whereas cognitive or social issues may suggest the need for simplification of a strategy component or enhanced supports (e.g., job aids) to decrease cognitive burden. Categories are not mutually exclusive, so a single usability issue may be classified into multiple categories as appropriate.

Example application. Following testing, the ratings and notes from each CWIS session were independently reviewed and analyzed by members of the research team who identified usability issues by independently identifying issues and then meeting to compare their coding, refine the list, and arrive at consensus judgments [61]. Next, they independently rated issue severity and complexity. Outcomes of the application of CWIS Step 6 to the MBC consultation protocol are presented in the results below.

\section{Results}

\section{Task Success}

Figure 3 presents a matrix of all subtasks rated by the participants, color coded based on their anticipated success ( 1 - very small chance of success [red], 2 - small chance of success [orange], 3 - probable chance of success [yellow] and 4 - very good chance of success [green]). The percentage of users who felt very confident in their anticipated success is highlighted in the rightmost column. Overall, ratings indicated substantial variability in anticipated success across participants and subtasks. Participants tended to rate their anticipated success knowing what to do (mean $=3.6$ ) and learning that they did it successfully (mean = 3.53) higher than their success actually completing the subtask (mean =3.29). Regarding specific subtasks, linking client intervention goals to an outcome monitoring plan received the lowest ratings. 


\section{Overall Strategy Usability}

ISUS ratings (scale: 0-100) ranged from 57.5 to 82.5 , with a mean of $71.3(S D=10.6)$. Mean ratings for each CWIS group were similar (73.1 vs. 70.0). Based on descriptors developed for the original System Usability Scale [56], this range corresponds to descriptors between "low marginal" (1st quartile) and "excellent" (4th quartile) [62]. The mean was in the lower end of the "acceptable" range.

\section{Usability Problems}

Consensus coding yielded 21 distinct usability problems. Usability issues included potential misalignment between consultation and clinical service timelines as well as the need for tools to support real-time decision-making during consultation. Table 3 displays each of these usability problems, organized based on average severity scores completed by three members of the research team. Overall, usability issues ranged from the most severe at 1.33 for Focus on barriers detracts from case presentation to 4.00 for Unfamiliar language in consultation model. Usability issues rated as the most severe (1.00-2.00) demonstrated a full range of complexity levels, but were primarily high or medium complexity and, with one exception, were identified by five or more participating users. Overall, the scope of the usability issues ranged from those that affected a single user (e.g., Case presentations exceed time allotted) to those that were identified by seven separate users (Unprepared to articulate monitoring targets). Application of the adapted enhanced cognitive walkthrough categorization approach [28] indicated that approximately half of the issues could be classified within multiple categories. Nine issues were determined to be related to the user, three issues were related to information being hidden, two issues were connected to sequencing or timing, three issues were due to insufficient feedback, and eleven issues reflected excessive cognitive or social demands.

\section{Discussion}

Complex and multifaceted implementation strategies are increasingly common in implementation science. The extent to which these strategies can be successfully applied by specified users to achieve their goals is a critical consideration when making decisions about implementation strategy selection and adaptation. Usability assessment has the potential to provide a key input into strategy adoption and tailoring decisions. CWIS is the first methodology developed to explicitly assess the usability of implementation strategies in healthcare.

\section{Cwis Findings For Post-training Consultation}

In the current example, the results of the ISUS indicated that clinician-rated usability of the original consultation protocol was at the low end of the acceptable range (based on existing SUS norms) and would benefit from some revision [63]. Although potentially workable for many users, this finding suggests that revisions to the strategy are likely indicated to improve ease of use and usefulness for its identified set of clinician primary users. 
In addition to ratings of overall usability, CWIS walkthrough sessions revealed 21 discrete usability issues. Collectively, these issues explain the ISUS quantitative usability data and provide specific direction for

usability enhancements. The identified usability issues were diverse with regard to their severity, complexity, scope, and classification. Most usability issues related either to whether the protocol had inaccurate expectations surrounding clinician preparation in consultation-related skills (e.g., Unprepared to identify solutions to barriers), various opportunities for consultation to be disrupted by participants who needed to discuss implementation barriers (e.g., Digressions derail barrier problem solving and engagement), the protocol's built-in assumptions about service delivery timelines (e.g., Rapid assessment misaligned with available time), or digital technology-related issues (e.g., Inadequate on-site technology).

\section{Implications For Strategy Redesign}

Much of the utility of the CWIS methodology comes from its potential to inform user-centered redesign of implementation strategies to ensure their usability. Although it is beyond the scope of this paper to articulate the full strategy adaptation process (where CWIS served as a key input), the results of the current example application indicated some clear redesign directions to improve the alignment of the consultation protocol with clinician users. Focusing redesign on the highest priority problems is intended to avoid excessive changes that may not be critical. As can be seen in Table 4, CWIS resulted in significant redesign of the consultation strategy in multiple ways that were unanticipated at the outset. The highest-rated usability issues were addressed through modifications to various consultation elements, and most redesign decisions addressed multiple usability issues. For example, the project team streamlined the consultation call time (reduced to no more than 50 minutes) and designed brief make-up sessions (15 minutes) to address the fact that the consultation protocol's expectations for regular calls (length and duration) was incompatible with their availability and preferences. In addition, assignment of a problem type classification to each usability issue further facilitated redesign. For instance, two of the three highest severity problems were categorized as issues related to the implementation strategy not being aligned with the users and their knowledge base (Focus on barriers detracts from case presentation and Unprepared to identify solutions to barriers). This indicated that additional specific supports surrounding consultation-relevant skills such as case presentations and problem-solving implementation barriers were important to improving overall usability. Modifications to address these issues included developing supplemental MBC resources, providing clear examples, and creating multiple opportunities to ask questions and get support (including asynchronously).

\section{Limitations}

Despite its utility, as evidenced above, the current application of CWIS has a number of limitations. First, our example application only involved applying CWIS to a single user group (clinician recipients of the strategy). Future applications may include professionals who deliver implementation strategies (e.g., expert consultants, especially those unaffiliated with the study team) in addition to the targets of those strategies. Second, the methodology was only applied to a single implementation strategy. Additional studies will help to broaden the number and types of strategies for which CWIS can inform redesign. Third, although it is 
designed to approximate the hands-on experience of using an implementation strategy, CWIS still involves some level of abstraction given that participating users do not actually complete the tasks on which they are reporting. This is a common tradeoff in cognitive walkthroughs and may be one reason why walkthrough methods sometimes over-identify usability problems [64]. Although this aspect of the method enhances the degree to which it is efficient and pragmatic, future work should determine whether group-based walkthroughs produce usability results that are comparable to more - or less - intensive (and expensive) types of testing. This may include one-on-one walkthroughs with individuals or other approaches [65]. Finally, pragmatic methods and instruments should ideally be sensitive to change [14], but the current study only involved applying CWIS at one point in the iterative development of the consultation strategy. Additional research should evaluate CWIS's change sensitivity.

\section{Conclusion}

Despite growing interest in implementation strategy selection and tailoring processes, no methods exist to evaluate usability and ensure that strategies can be successfully applied by well-specified users in their contexts of use. The current study provides preliminary evidence for the utility of CWIS to assess strategy usability and generate a blueprint for redesign. Future work should evaluate the extent to which usability, as measured by CWIS, is predictive of the fidelity with which implementation strategies (e.g., training, consultation, leadership supports) are delivered as well as their impact on implementation and health service outcomes.

\section{Abbreviations}

\section{ACTS}

Accelerated Creation to Sustainment

\section{ALACRITY}

Advanced Laboratory for Accelerating the Reach and Impact of Treatments for Youth and Adults with Mental IIIness

\section{CWIS}

Cognitive Walkthrough for Implementation Strategies

\section{DDBT}

Discover, Design/Build, Test framework

\section{EBPs}

Evidence-based practices

HCD

Human-Centered Design

ISUS

Implementation Strategy Usability Scale

MBC

Measurement-based care 


\section{Declarations}

\section{Ethics approval and consent to participate}

This project was approved by the University of Washington Institutional Review Board (IRB).

\section{Consent for publication}

Not applicable.

\section{Availability of data and materials}

Please contact the lead author for more information.

\section{Competing interests}

All authors declare that they have no completing interests.

\section{Funding}

This publication was supported by grants R34MH109605 and P50MH115837, awarded by the National Institute of Mental Health. The content is solely the responsibility of the authors and does not necessarily represent the official views of the National Institutes of Health.

\section{Authors' contributions}

ARL and EM developed the overarching scientific aims and design of the project. JC, HC, and EM assisted in the operationalization of the study methods, worked with ARL and EM to obtain institutional review board approval, and supported study recruitment, data collection, and analyses. FF, KL, SD, and KK supported the development of the post-training consultation protocol, as well as task analysis and prioritization. ARL, JC, HC, and EM conducted qualitative coding, identified usability issues, and prepared the study results. All authors contributed to the development, drafting, or review of the manuscript. All authors approved the final manuscript.

\section{Acknowledgements}

Thank you to Ethan Hendrix for supporting data collection for this project.

\section{References}

1. Balas EA, Boren SA. Managing clinical knowledge for health care improvement. Yearb Med Inform. 2000;(1):65-70. doi:10.1055/s-0038-1637943.

2. Eccles MP, Mittman BS. Welcome to implementation science. Implement Sci. 2006 Feb;22(1):1. doi:10.1186/1748-5908-1-1. 1 ) . 
3. Powell BJ, McMillen JC, Proctor EK, Carpenter CR, Griffey RT, Bunger AC, et al. A compilation of strategies for implementing clinical innovations in health and mental health. Med Care Res Rev. 2012;69(2):123-57. doi:10.1177/1077558711430690.

4. Lyon AR, Munson SA, Renn BN, Atkins DC, Pullmann MD, Friedman E, et al. Use of human-centered design to improve implementation of evidence-based psychotherapies in low-resource communities: Protocol for studies applying a framework to assess usability. JMIR Res Protoc. 2019;8(10):e14990. doi:10.2196/14990.

5. Powell BJ, Waltz TJ, Chinman MJ, Damschroder LJ, Smith JL, Matthieu MM, et al. A refined compilation of implementation strategies: Results from the Expert Recommendations for Implementing Change (ERIC) project. Implement Sci. 2015;10(1):21. doi:10.1186/s13012-015-0209-1.

6. Proctor EK, Powell BJ, McMillen JC. Implementation strategies: Recommendations for specifying and reporting. Implement Sci. 2013;8(1):139. doi:10.1186/1748-5908-8-139.

7. Aarons GA, Powell BJ, Beidas RS, Lewis CC, McMillen JC, Proctor EK, et al. Methods to improve the selection and tailoring of implementation strategies. J Behav Health Serv Res. 2017;44(2). doi:10.1007/s11414-015-9475-6.

8. Glisson C, Schoenwald SK. The ARC organizational and community intervention strategy for implementing evidence-based children's mental health treatments. Ment Health Serv Res. 2005;7(4):243-59. doi:10.1007/s11020-005-7456-1.

9. Kilbourne AM, Neumann MS, Pincus HA, Bauer MS, Stall R. Implementing evidence-based interventions in health care: Application of the replicating effective programs framework. Implement Sci. 2007;2(1):42. doi:10.1186/1748-5908-2-42.

10. Beidas RS, Kendall PC. Training therapists in evidence-based practice: A critical review of studies from a systems-contextual perspective. Clin Psychol Sci Pract. 2010;17(1):1-30. https://doi.org/10.1111/j.1468-2850.2009.01187.x.

11. Oxman AD, Thomson MA, Davis DA, Haynes RB. No magic bullets: A systematic review of 102 trials of interventions to improve professional practice. Can Med Assoc J. 1995;152:1423-31.

12. Baker R, Camosso-Stefinovic J, Gillies C, Shaw EJ, Cheater F, Flottorp S, et al. Tailored interventions to overcome identified barriers to change: Effects on professional practice and health care outcomes. Cochrane Database Syst Rev. 2010;(3).

13. doi: 10.1002/14651858.CD005470.pub2.

14. Wensing M, Bosch MC, Grol R. Selecting, tailoring, and implementing knowledge translation interventions. Knowledge Translation in Health Care: Moving from evidence to practice. United Kingdom: Wiley-Blackwell; 2009;pp. 94-113. doi:10.1503/cmaj.081335.

15. Glasgow RE. What does it mean to be pragmatic? Pragmatic methods, measures, and models to facilitate research translation. Health Educ Behav. 2013;40(3):257-65. doi:10.1177/1090198113486805.

16. Stanick CF, Halko HM, Dorsey CN, Weiner BJ, Powell BJ, Palinkas LA, et al. Operationalizing the 'pragmatic' measures construct using a stakeholder feedback and a multi-method approach. BMC Health Serv Res. 2018;18(1):882. doi:10.1186/s12913-018-3709-2. 
17. Courage C, Baxter K. Understanding your users: A practical guide to user requirements methods, tools, and techniques. Gulf Professional Publishing; 2005.

18. https://doi.org/10.1016/B978-1-55860-935-8.X5029-5.

19. Norman DA, Draper SW. User centered system design; New perspectives on human-computer interaction. USA: L. Erlbaum Associates Inc.; 1986. doi:10.1201/b15703.

20. Roberts JP, Fisher TR, Trowbridge MJ, Bent C. A design thinking framework for healthcare management and innovation. Healthcare. 2016;4(1):11-4. doi:10.1016/j.hjdsi.2015.12.002.

21. Mohr DC, Lyon AR, Lattie EG, Reddy M, Schueller SM. Accelerating digital mental health research from early design and creation to successful implementation and sustainment. J Med Internet Res. 2017;19(5):e153. doi:10.2196/jmir.7725.

22. International Standards Organization. Part 11: Guidance on usability. In: Ergonomic requirements for office work with visual display terminals (VDTs). 1st ed. 1998. doi:10.3403/01879403.

23. Eisman AB, Kilbourne AM, Greene $D$, Walton $M$, Cunningham R. The user-program interaction: How teacher experience shapes the relationship between intervention packaging and fidelity to a stateadopted health curriculum. Prev Sci. 2020;1-10. doi:10.1007/s11121-020-01120-8.

24. Lyon AR, Bruns EJ. User-centered redesign of evidence-based psychosocial interventions to enhance implementation-hospitable soil or better seeds? JAMA Psychiatry. 2019;76(1):3-4. doi:10.1001/jamapsychiatry.2018.3060.

25. Dopp AR, Parisi KE, Munson SA, Lyon AR. Aligning implementation and user-centered design strategies to enhance the impact of health services: Results from a concept mapping study. Implement Sci Commun. 2020;1(1):17. doi:10.1186/s43058-020-00020-w.

26. Lyon AR, Brewer SK, Arean PA. Leveraging human-centered design to implement modern psychological science: Return on an early investment. Am Psychol. 2020;75(8):1067-79. http://dx.doi.org/10.1037/amp0000652.

27. Lavery D, Cockton G, Atkinson MP. Comparison of evaluation methods using structured usability problem reports. Behav Inf Technol. 1997;16(4-5):246-66. doi:10.1080/014492997119824.

28. Mahatody T, Sagar M, Kolski C. State of the art on the cognitive walkthrough method, its variants and evolutions. Int J Human-Computer Interact. 2010;26(8):741-85. doi:10.1080/10447311003781409.

29. Rieman J, Franzke M, Redmiles D. Usability evaluation with the cognitive walkthrough. In: Proceedings of the SIGCHI Conference on Human Factors in Computing Systems. Denver, CO; 1995. 387-388. https://doi.org/10/1145/223355.223735.

30. Bligård LO, Osvalder AL. Enhanced cognitive walkthrough: Development of the cognitive walkthrough method to better predict, identify, and present usability problems. Advances in Human-Computer Interaction. 2013. https://doi.org/10.1155/2013/931698.

31. Gutwin C, Greenberg S. The mechanics of collaboration: Developing low cost usability evaluation methods for shared workspaces. Proceedings of the 9th IEEE International Workshops on Enabling Technologies: Infrastructure for Collaborative Enterprises. Washington, DC, USA: IEEE Computer Society; 2000;98-103. doi:10.1109/ENABL.2000.883711. 
32. Duong MT, Bruns EJ, Lee K, Cox S, Coifman J, Mayworm A, et al. Rates of mental health service utilization by children and adolescents in schools and other common service settings: A systematic review and meta-analysis. Adm Policy Ment Health Ment Health Serv Res. 2020. doi:10.1007/s10488020-01080-9.

33. Farmer EMZ, Burns BJ, Phillips SD, Angold A, Costello EJ. Pathways into and through mental health services for children and adolescents. Psychiatr Serv. 2003;54(1):60-6. doi:10.1175/appi.ps.54.1.60.

34. Scott K, Lewis CC. Using measurement-based care to enhance any treatment. Cogn Behav Pract. 2015;22(1):49-59. doi:10.1016/j.cbpra.2014.01.010.

35. Fortney JC, Unützer J, Wrenn G, Pyne JM, Smith GR, Schoenbaum M, et al. A tipping point for measurement-based care. Psychiatr Serv. 2017;68(2):179-88. doi:10.1176/appi.ps.201500439.

36. Lewis CC, Boyd M, Puspitasari A, Navarro E, Howard J, Kassab H, et al. Implementing measurementbased care in behavioral health: A review. JAMA Psychiatry. 2019;76(3):324-35. doi:10.1001/jamapsychiatry.2018.3329.

37. Stephan SH, Sugai G, Lever N, Connors E. Strategies for integrating mental health into schools via a multitiered system of support. Child Adolesc Psychiatr Clin N Am. 2015;24(2):211-31. doi:10.1016/j.chc.2014.12.002.

38. Lyon AR, Lewis CC, Boyd MR, Hendrix E, Liu F. Capabilities and characteristics of digital measurement feedback systems: Results from a comprehensive review. Adm Policy Ment Health Ment Health Serv Res. 2016;43(3):441-66. doi:10.1007/s10488-016-0719-4.

39. Glasgow RE, Riley WT. Pragmatic measures: What they are and why we need them. Am J Prev Med. 2013;45(2):237-43. doi:10.1016/j.amepre.2013.03.010.

40. Conners-Burrow NA, McKelvey LM, Fussell JJ. Social outcomes associated with media viewing habits of low-income preschool children. Early Educ Dev. 2011;22(2):256-73. doi:10.1080/10409289.2011.550844.

41. Wisdom JP, Olin S, Shorter P, Burton G, Hoagwood K. Family peer advocates: A pilot study of the content and process of service provision. J Child Fam Stud. 2011;20(6):833-43. doi:10.1007/s10826-011-94516.

42. Nadeem E, Gleacher A, Beidas RS. Consultation as an implementation strategy for evidence-based practices across multiple contexts: Unpacking the black box. Adm Policy Ment Health Ment Health Serv Res. 2013;40(6):439-50. doi:10.1007/s10488-013-0502-8.

43. Herschell AD, Kolko DJ, Baumann BL, Davis AC. The role of therapist training in the implementation of psychosocial treatments: A review and critique with recommendations. Clin Psychol Rev. 2010;30(4):448-66. doi:10.1016/j.cpr.2010.02.005.

44. Lyon AR, Charlesworth-Attie S, Vander Stoep A, McCauley E. Modular psychotherapy for youth with internalizing problems: Implementation with therapists in school-based health centers. Sch Psychol Rev. 2011. doi:10.1080/02796015.2011.12087530.

45. Edmunds JM, Beidas RS, Kendall PC. Dissemination and implementation of evidence-based practices: Training and consultation as implementation strategies. Clin Psychol Sci Pract. 2013;20(2):152-65. doi:10.1111/cpsp.12031. 
46. Lyon AR, Pullmann MD, Walker SC, D’Angelo G. Community-sourced intervention programs: Review of submissions in response to a statewide call for "promising practices. Adm Policy Ment Health Ment Health Serv Res. 2017;44(1):16-28. doi:10.1007/s10488-015-0650-0.

47. Lewis CC, Klasnja P, Powell BJ, Lyon AR, Tuzzio L, Jones S, et al. From classification to causality: Advancing understanding of mechanisms of change in implementation science. Front Public Health. 2018;6:136. doi:10.3389/fpubh.2018.00136.

48. Cooper A, Reimann R, Cronin D. About Face 3: The essentials of interaction design. 3rd edition. Indianapolis, IN: Wiley; 2007.

49. Cooper A. The inmates are running the asylum. Macmillan Publishing Co., Inc.; 1999. doi:10.1007/9783-322-99786-9_1.

50. Kujala S, Mäntylä M. How effective are user studies? In: McDonald S, Waern Y, Cockton G, editors. People and Computers XIV - Usability or Else! Springer London; 2000; 61-71. doi:10.1007/978-1-44710515-2_5.

51. Grudin J, Pruitt J. Personas, participatory design and product development: An infrastructure for engagement. Palo Alto: Computer Professionals for Social Responsibility; 2002. pp. 144-52.

52. Shepherd A. HTA as a framework for task analysis. Ergonomics. 1989;41(11):1537-52. doi:10.1080/001401398186063.

53. Jonassen DH, Tessmer M, Hannum WH. Task analysis methods for instructional design. Routledge; 1998. doi:10.4324/9781410602657.

54. Wei J, Salvendy G. The cognitive task analysis methods for job and task design: Review and reappraisal. Behav Inf Technol. 2004;23(4):273-99. doi:10.1080/01449290410001673036.

55. Klein G, Militello L. Some guidelines for conducting a cognitive task analysis. Adv Hum Perform Cogn Eng Res. 1998;1:161-99. doi:10.1016/S1479-3601(01)01006-2.

56. Lyon AR, Koerner K. User-centered design for psychosocial intervention development and implementation. Clin Psychol Sci Pract. 2016;23(2):180-200. doi:10.1111/cpsp.12154.

57. Aarons GA, Ehrhart MG, Farahnak LR, Hurlburt MS. Leadership and organizational change for implementation (LOCI): A randomized mixed method pilot study of a leadership and organization development intervention for evidence-based practice implementation. Implement Sci. 2015;10(1):11. doi:10.1186/s13012-014-0192-y.

58. Brooke J. SUS: A quick and dirty usability scale. Usability Evaluation in Industry. London: Taylor and Francis; 1996. doi:10.1201/9781498710411-35.

59. Sauro J. A practical guide to the system usability scale: Background, benchmarks \& best practices. Measuring Usability LLC; 2011.

60. Lyon AR. Usability testing and reporting at the UW ALACRITY Center. Association for Behavioral and Cognitive Therapies Meeting; 2020.

61. Dumas JS, Redish J. A practical guide to usability testing. Intellect Books; 1999. doi:10.5555/600280.

62. Albert W, Dixon E. Is this what you expected? The use of expectation measures in usability testing. Proceedings of the Usability Professionals Association 2003 Conference, Scottsdale, AZ. 2003. 
63. Hill CE, Knox S, Thompson BJ, Williams EN, Hess SA, Ladany N. Consensual qualitative research: An update. J Couns Psychol. 2005;52(2):196-205. doi:10.1037/0022-0167.52.2.196.

64. Bangor A, Kortum PT, Miller JT. An empirical evaluation of the System Usability Scale. Int J HumanComputer Interact. 2008;24(6):574-94. doi:10.1080/10447310802205776.

65. Kortum PT, Bangor A. Usability ratings for everyday products measured with the System Usability Scale. Int J Human-Computer Interact. 2013;29(2):67-76. doi:10.1080/10447318.2012.681221.

66 . Health and Human Services. Use cognitive walkthroughs cautiously usability guidelines. https://webstandards.hhs.gov/guidelines/204. n.d.

67. Lyon AR, Koerner K, Chung J. Usability Evaluation for Evidence-Based Psychosocial Interventions (USEEBPI): A methodology for assessing complex intervention implementability. Implement Res Pract. 2020. doi:10.1177/2633489520932924.

\section{Tables}


Table 1. Prioritization of consultation tasks

\begin{tabular}{|c|c|c|}
\hline Task & $\begin{array}{l}\text { Importance } \\
\text { Mean Rating }\end{array}$ & $\begin{array}{l}\text { Likelihood } \\
\text { of Error } \\
\text { Mean } \\
\text { Rating }\end{array}$ \\
\hline
\end{tabular}

Access digital materials (obtain internet access, access/navigate modules or message board

5.0

4.0

Selected for testing

Present 1 st MBC case (succinctly summarize case features/MBC plan, select assessment instrument OR 5.0

4.0

Selected for describe results of initial assessment, describe rationale for ongoing assessments, articulate what a positive response would look like OR describe results of ongoing assessments, describe next steps for MBC with the case)

Articulate possible barriers/concerns with MBC for identified cases (identify barriers, articulate likelihood of each barrier, problem-solve barrier with consultant: generate solutions, select a solution to apply)

Plan for maintenance of behavior change (articulate additional barriers to MBC, problem-solve barriers with consultation group: generate solutions, select a solution to apply)

Login to message board (access user name/password info, type user name/password successfully)

4.8

3.5 testing

4.5

Selected for testing

Selected for testing

$\begin{array}{lll}4.5 & 4.0 & \begin{array}{l}\text { Selected for } \\ \text { testing }\end{array}\end{array}$

3.5

Deprioritized (entirely digital process)

Revise planned MBC steps with case based on feedback/discussion (change monitoring target for MBC cases: revisit goals/select alternative targets/articulate plan to present alternative targets to case, select alternative cases for MBC) Selected for testing

Navigate to message board from 1+ location 4.0 3.3

4

3.3

Deprioritized
(entirely
digital
process)

Articulate questions/problems encountered RE: MBC skill application (identify specific BOLT map step where assistance is needed, respond to consultant questions clarifying details about skill application: what have they tried/what are they trying to achieve/what has been problematic, *role play MBC conversation

2nd or 3rd case presentation (succinctly summarize 3.8

4.0 2.5

case features/MBC plan, select assessment instrument

OR describe results of initial assessment, describe rationale for ongoing assessments, articulate what a positive response would look like OR describe results of ongoing assessments, describe next steps for MBC with the case) 


\begin{tabular}{|c|c|c|}
\hline Navigate to appropriate discussion thread & 3.8 & 3.0 \\
\hline Read trainee and consultant posts within a thread & 3.8 & 2.8 \\
\hline $\begin{array}{l}\text { Discuss non-completion of practice activity (generate } \\
\text { reasons, problem solve: generate solutions, select } \\
\text { solution to apply) }\end{array}$ & 3.5 & 3.3 \\
\hline $\begin{array}{l}\text { Complete values activity (articulate professional } \\
\text { values, articulate barriers, articulate if/then plan linking } \\
\text { barriers to correction actions) }\end{array}$ & 3.5 & 3.3 \\
\hline Post practice activity results & 3.3 & 3.7 \\
\hline Schedule make-up calls & 3.3 & 3.3 \\
\hline $\begin{array}{l}\text { Identify/post cases to serve as MBC targets (review } \\
\text { cases to ID those appropriate for MBC, post succinct } \\
\text { case examples on message board) }\end{array}$ & 3.3 & 2.3 \\
\hline $\begin{array}{l}\text { Give Introduction (wait turn/speak at appropriate time, } \\
\text { present info, report practice activity, summarize } \\
\text { practice activity) }\end{array}$ & 3.3 & 2.0 \\
\hline $\begin{array}{l}\text { Record new practice/homework assignment to be } \\
\text { posted to message board }\end{array}$ & 3.0 & 2.8 \\
\hline Other practice/homework activities & 2.8 & 2.8 \\
\hline $\begin{array}{l}\text { Provide feedback on others' posts/MBC application } \\
\text { questions (identify relevant BOLT map steps) }\end{array}$ & 2.5 & 3.0 \\
\hline Email consultants with questions & 2.5 & 2.0 \\
\hline $\begin{array}{l}\text { Revise an existing MBC script to tailor to personal } \\
\text { style/student population }\end{array}$ & 2.5 & 1.8 \\
\hline $\begin{array}{l}\text { Provide constructive feedback to other trainees (wait } \\
\text { turn/speak at appropriate time, describe ideas about } \\
\text { MBC application) }\end{array}$ & 2.3 & 2.8 \\
\hline Document questions/concerns as they arise & 1.8 & 2.3 \\
\hline
\end{tabular}




\begin{tabular}{|lll|}
\hline Table 2. Clinician Demographics & & \\
\hline Gender & $N$ & $\%$ \\
\hline Male & & \\
\hline Female & 1 & 10 \\
\hline Race & 9 & 90 \\
\hline Aboriginal (First Nations, Metis, Inuit) & 0 & \\
\hline Native Hawaiian or other Pacific Islander & 0 & \\
\hline Black or African American & 0 & \\
\hline Asian & 2 & 20 \\
\hline White or Caucasian & 7 & 70 \\
\hline Latino & 1 & 10 \\
\hline Highest degree earned & & \\
\hline Master's & 10 & 100 \\
\hline Age & & \\
\hline $25-34$ & 4 & 40 \\
\hline $35-44$ & 5 & 50 \\
\hline $45-54$ & 0 & \\
\hline $55-64$ & 1 & 10 \\
\hline Years in role & 3 & 30 \\
\hline Less than 5 years & 3 & 30 \\
\hline $11-15$ years & 1 & 10 \\
\hline
\end{tabular}


Table 3. Prioritization \& categorization of usability problems

\section{Severity Complexity Scope Abbreviated UP Usability problem Problem Types rating}

\begin{tabular}{|c|c|c|c|c|c|c|c|c|c|}
\hline 1.33 & high & 2 & $\begin{array}{l}\text { Focus on } \\
\text { barriers detracts } \\
\text { from case } \\
\text { presentation }\end{array}$ & $\begin{array}{l}\text { During initial case } \\
\text { presentations, } \\
\text { clinicians tend to } \\
\text { focus on barriers to } \\
\text { actually applying } \\
\text { MBC, potentially } \\
\text { detracting from other } \\
\text { important topics of } \\
\text { discussion and } \\
\text { decreasing } \\
\text { motivation to } \\
\text { implement MBC } \\
\text { (inferred). }\end{array}$ & U & $\mathrm{H}$ & ST & $F$ & CS \\
\hline 1.67 & medium & 5 & $\begin{array}{l}\text { Unprepared to } \\
\text { identify } \\
\text { solutions to } \\
\text { barriers }\end{array}$ & $\begin{array}{l}\text { When generating } \\
\text { solutions to perceived } \\
\text { barriers to using MBC } \\
\text { during late-stage } \\
\text { consultation calls, } \\
\text { clinicians don't feel } \\
\text { prepared to identify } \\
\text { appropriate/insightful } \\
\text { solutions in the } \\
\text { moment, leaving } \\
\text { them unsure how to } \\
\text { proceed (stated), and } \\
\text { discouraged or } \\
\text { unmotivated to use } \\
\text { MBC (inferred). }\end{array}$ & U & $\mathrm{H}$ & ST & $\mathrm{F}$ & CS \\
\hline
\end{tabular}

\begin{tabular}{|c|c|c|c|c|c|c|c|c|c|}
\hline 1.67 & medium & 7 & $\begin{array}{l}\text { Inadequate on- } \\
\text { site technology }\end{array}$ & $\begin{array}{l}\text { Consultation calls } \\
\text { employ } \\
\text { videoconference } \\
\text { technologies and } \\
\text { equipment, but some } \\
\text { clinicians do not have } \\
\text { necessary hardware } \\
\text { or technological } \\
\text { supports, which } \\
\text { might detract from } \\
\text { the level of } \\
\text { engagement or ability } \\
\text { to participate during } \\
\text { the calls (inferred). }\end{array}$ & U & $\mathrm{H}$ & ST & $F$ & CS \\
\hline 2.00 & medium & 5 & $\begin{array}{l}\text { Rapid } \\
\text { assessment } \\
\text { misaligned with } \\
\text { available time }\end{array}$ & $\begin{array}{l}\text { The consultation } \\
\text { protocol assumes a } \\
\text { rapid assessment } \\
\text { and feedback process } \\
\text { between meetings to } \\
\text { identify treatment } \\
\text { goals ( } 4 \text { weeks), } \\
\text { which clinicians } \\
\text { experienced as } \\
\text { shorter than amount } \\
\text { of time often allotted, }\end{array}$ & U & $\mathrm{H}$ & ST & $F$ & CS \\
\hline
\end{tabular}




\begin{tabular}{|c|c|c|c|c|c|c|c|c|c|}
\hline & & & & $\begin{array}{l}\text { creating a barrier to } \\
\text { implementing MBC } \\
\text { (stated) and/or } \\
\text { decreased } \\
\text { engagement with } \\
\text { consultation } \\
\text { (inferred). }\end{array}$ & & & & & \\
\hline 2.00 & high & 5 & $\begin{array}{l}\text { Digressions } \\
\text { derail barrier } \\
\text { problem solving } \\
\text { and } \\
\text { engagement }\end{array}$ & $\begin{array}{l}\text { When clinicians are } \\
\text { asked to articulate } \\
\text { and prioritize } \\
\text { perceived barriers to } \\
\text { applying MBC, they } \\
\text { frequently digress, } \\
\text { resulting in other } \\
\text { clinicians } \\
\text { disengaging from the } \\
\text { call (stated), worries } \\
\text { about describing } \\
\text { contextual } \\
\text { constraints of their } \\
\text { roles (stated), and } \\
\text { uncertainty about } \\
\text { quality of feedback } \\
\text { that is contingent on } \\
\text { their ability to } \\
\text { adequately present } \\
\text { information (stated). }\end{array}$ & U & $\mathrm{H}$ & ST & $F$ & CS \\
\hline 2.00 & low & 7 & $\begin{array}{l}\text { Unprepared to } \\
\text { articulate } \\
\text { updated } \\
\text { monitoring } \\
\text { targets }\end{array}$ & $\begin{array}{l}\text { When prompted to } \\
\text { articulate their plan to } \\
\text { present updated } \\
\text { monitoring targets to } \\
\text { the student, clinicians } \\
\text { feel put on the spot } \\
\text { and question the } \\
\text { quality of the } \\
\text { feedback they are } \\
\text { receiving, resulting in } \\
\text { less confidence } \\
\text { (stated) and } \\
\text { unwillingness to } \\
\text { participate in the call } \\
\text { (inferred). }\end{array}$ & U & $\mathrm{H}$ & ST & $F$ & CS \\
\hline 2.33 & low & 2 & $\begin{array}{l}\text { No storage for } \\
\text { barrier solutions }\end{array}$ & $\begin{array}{l}\text { When articulating } \\
\text { possible solutions to } \\
\text { anticipated barriers, } \\
\text { clinicians had no } \\
\text { clear place to store } \\
\text { their recorded } \\
\text { solutions, decreasing } \\
\text { the likelihood that } \\
\text { they would be able to } \\
\text { access the solutions } \\
\text { at a later time } \\
\text { (stated). }\end{array}$ & U & H & ST & $\mathrm{F}$ & CS \\
\hline 2.33 & high & 2 & $\begin{array}{l}\text { Regular calls } \\
\text { incompatible }\end{array}$ & $\begin{array}{l}\text { The consultation call } \\
\text { model expects } \\
\text { clinicians to attend }\end{array}$ & U & $\mathrm{H}$ & ST & $F$ & CS \\
\hline
\end{tabular}




\begin{tabular}{|c|c|c|c|c|c|c|c|c|c|}
\hline & & & $\begin{array}{l}\text { with } \\
\text { time/availability }\end{array}$ & $\begin{array}{l}\text { regular/scheduled } \\
\text { calls, which clinicians } \\
\text { find incompatible } \\
\text { with their time and } \\
\text { availability, which } \\
\text { might lead to lower } \\
\text { participation } \\
\text { (inferred). }\end{array}$ & & & & & \\
\hline 2.67 & medium & 1 & $\begin{array}{l}\text { Case } \\
\text { presentations } \\
\text { exceed time } \\
\text { allotted }\end{array}$ & $\begin{array}{l}\text { During initial case } \\
\text { presentations, stated } \\
\text { call expectations that } \\
\text { presentations are } \\
\text { brief (i.e., } 1-3 \\
\text { minutes) results in } \\
\text { clinicians potentially } \\
\text { exceeding the time } \\
\text { allotted (stated), } \\
\text { which might detract } \\
\text { from other important } \\
\text { topics of discussion } \\
\text { (inferred). }\end{array}$ & $U$ & $\mathrm{H}$ & ST & $\mathrm{F}$ & CS \\
\hline 3.00 & medium & 5 & $\begin{array}{l}\text { Unfamiliar case } \\
\text { update structure }\end{array}$ & $\begin{array}{l}\text { When providing case } \\
\text { updates on } \\
\text { subsequent calls, the } \\
\text { case presentation } \\
\text { structure (i.e., } \\
\text { providing rationale, } \\
\text { positive intervention } \\
\text { response, and next } \\
\text { steps) may be } \\
\text { unfamiliar and a } \\
\text { deviation from the } \\
\text { case presentation } \\
\text { approaches clinicians } \\
\text { are used to, resulting } \\
\text { in wariness and a } \\
\text { lack of confidence } \\
\text { (stated). }\end{array}$ & U & $\mathrm{H}$ & ST & $\mathrm{F}$ & CS \\
\hline 3.00 & medium & 4 & $\begin{array}{l}\text { Duration } \\
\text { misaligned with } \\
\text { preferences }\end{array}$ & $\begin{array}{l}\text { The consultation call } \\
\text { model may be too } \\
\text { brief to align with } \\
\text { clinicians' stated } \\
\text { preferences needing } \\
\text { longer overall } \\
\text { duration of } \\
\text { consultation, } \\
\text { potentially leading to } \\
\text { a sense of lack of } \\
\text { confidence and } \\
\text { support (inferred) to } \\
\text { effectively implement } \\
\text { MBC. }\end{array}$ & $U$ & $\mathrm{H}$ & ST & $\mathrm{F}$ & CS \\
\hline 3.00 & low & 3 & $\begin{array}{l}\text { No continued } \\
\text { access to } \\
\text { resources }\end{array}$ & $\begin{array}{l}\text { Upon concluding live } \\
\text { consultation, } \\
\text { clinicians experienced } \\
\text { concerns over the } \\
\text { absence of continued }\end{array}$ & $U$ & $\mathrm{H}$ & ST & $\mathrm{F}$ & CS \\
\hline
\end{tabular}




\begin{tabular}{|c|c|c|c|c|c|c|c|c|c|}
\hline & & & & $\begin{array}{l}\text { access to resources } \\
\text { (guidance, training, } \\
\text { etc.) and peer } \\
\text { discourse, which } \\
\text { might result in feeling } \\
\text { a lack of support or } \\
\text { uncertainty in how to } \\
\text { proceed with MBC } \\
\text { (inferred). }\end{array}$ & & & & & \\
\hline 3.33 & low & 2 & $\begin{array}{l}\text { Discomfort with } \\
\text { assessments in } \\
\text { case } \\
\text { presentations }\end{array}$ & $\begin{array}{l}\text { During initial case } \\
\text { presentations, } \\
\text { clinicians experience } \\
\text { potential discomfort } \\
\text { presenting } \\
\text { information from } \\
\text { MBC assessments } \\
\text { that they have not yet } \\
\text { mastered, leading to } \\
\text { less confidence in } \\
\text { implementing MBC } \\
\text { (inferred). }\end{array}$ & $\mathbf{U}$ & $\mathrm{H}$ & ST & $F$ & CS \\
\hline 3.33 & low & 4 & $\begin{array}{l}\text { Confusion over } \\
\text { MBC } \\
\text { terminology }\end{array}$ & $\begin{array}{l}\text { When presenting the } \\
\text { results of } \\
\text { standardized } \\
\text { assessments during } \\
\text { initial case } \\
\text { presentations, } \\
\text { clinicians experience } \\
\text { confusion over the } \\
\text { terminology } \\
\text { (established norms, } \\
\text { clinically significant) } \\
\text { that is foundation for } \\
\text { MBC which could } \\
\text { lead to less } \\
\text { confidence in using } \\
\text { MBC practices } \\
\text { (inferred), } \\
\text { disengagement from } \\
\text { the calls (inferred), } \\
\text { and interfere with } \\
\text { accurate score } \\
\text { interpretation for } \\
\text { students on their } \\
\text { caseloads (stated). }\end{array}$ & $\mathrm{U}$ & $\mathrm{H}$ & ST & $F$ & CS \\
\hline 3.33 & medium & 4 & $\begin{array}{l}\text { Confidentiality } \\
\text { concerns when } \\
\text { reporting results }\end{array}$ & $\begin{array}{l}\text { When presenting the } \\
\text { results of } \\
\text { standardized } \\
\text { assessments during } \\
\text { initial case } \\
\text { presentations, } \\
\text { clinicians are } \\
\text { concerned over } \\
\text { privacy and } \\
\text { confidentiality } \\
\text { (stated), which may } \\
\text { have a negative } \\
\text { impact on their }\end{array}$ & $U$ & $\mathrm{H}$ & ST & $\mathrm{F}$ & CS \\
\hline
\end{tabular}




\begin{tabular}{|c|c|c|c|c|c|c|c|c|c|}
\hline & & & & $\begin{array}{l}\text { confidence and } \\
\text { interest in } \\
\text { participating in group } \\
\text { calls (inferred). }\end{array}$ & & & & & \\
\hline 3.33 & medium & 1 & $\begin{array}{l}\text { Difficulty } \\
\text { articulating } \\
\text { what's being } \\
\text { measured }\end{array}$ & $\begin{array}{l}\text { When reporting on } \\
\text { individualized goals } \\
\text { (and not on } \\
\text { standardized } \\
\text { measures), clinicians } \\
\text { struggle to articulate } \\
\text { what they're } \\
\text { measuring, which } \\
\text { results in hesitation } \\
\text { (inferred) and fear of } \\
\text { reporting incorrectly } \\
\text { (inferred). }\end{array}$ & $\mathbf{U}$ & $\mathrm{H}$ & ST & $F$ & CS \\
\hline 3.33 & high & 1 & $\begin{array}{l}\text { Constraints on } \\
\text { access to } \\
\text { school } \\
\text { buildings/ } \\
\text { students }\end{array}$ & $\begin{array}{l}\text { When discussing } \\
\text { solutions for } \\
\text { addressing perceived } \\
\text { barriers during late- } \\
\text { stage consultation } \\
\text { calls, clinicians from } \\
\text { outside community } \\
\text { mental health } \\
\text { agencies have more } \\
\text { constraints } \\
\text { surrounding their } \\
\text { access to school } \\
\text { buildings and } \\
\text { students, which } \\
\text { results in more } \\
\text { limitations (and less } \\
\text { control) surrounding } \\
\text { the execution of their } \\
\text { identified solutions. }\end{array}$ & $U$ & $\mathrm{H}$ & ST & $\mathrm{F}$ & CS \\
\hline 3.33 & medium & 5 & $\begin{array}{l}\text { Distraction from } \\
\text { multi-tasking } \\
\text { online during } \\
\text { calls }\end{array}$ & $\begin{array}{l}\text { When navigating } \\
\text { online training } \\
\text { resources (i.e. the } \\
\text { online message } \\
\text { board) during the call, } \\
\text { clinicians might get } \\
\text { distracted or struggle } \\
\text { to follow the call } \\
\text { discussion, which } \\
\text { might negatively } \\
\text { impact group } \\
\text { discourse or } \\
\text { engagement } \\
\text { (inferred). }\end{array}$ & $\mathbf{U}$ & $\mathrm{H}$ & ST & $F$ & CS \\
\hline 3.33 & low & 2 & $\begin{array}{l}\text { Unaware of } \\
\text { available follow } \\
\text { up supports }\end{array}$ & $\begin{array}{l}\text { When identifying the } \\
\text { most potentially } \\
\text { impactful barriers to } \\
\text { MBC during late- } \\
\text { stage calls, clinicians } \\
\text { are unaware what } \\
\text { follow up/feedback is } \\
\text { available after the }\end{array}$ & $U$ & $\mathrm{H}$ & ST & $F$ & CS \\
\hline
\end{tabular}




\begin{tabular}{|c|c|c|c|c|c|c|c|c|c|}
\hline & & & & $\begin{array}{l}\text { call is finished, } \\
\text { resulting in a sense of } \\
\text { lack of support } \\
\text { (inferred). }\end{array}$ & & & & & \\
\hline 4.00 & medium & 2 & $\begin{array}{l}\text { Technological } \\
\text { difficulties are } \\
\text { disengaging }\end{array}$ & $\begin{array}{l}\text { When having } \\
\text { technological } \\
\text { difficulties (login, } \\
\text { access to resources, } \\
\text { etc.) on the } \\
\text { consultation call, } \\
\text { clinicians might feel } \\
\text { distracted and } \\
\text { disengaged them } \\
\text { from the call } \\
\text { discussion and be } \\
\text { prevented from } \\
\text { accessing necessary } \\
\text { resources (inferred). }\end{array}$ & U & $\mathrm{H}$ & ST & $\mathrm{F}$ & CS \\
\hline 4.00 & low & 3 & $\begin{array}{l}\text { Unfamiliar } \\
\text { language in } \\
\text { consultation } \\
\text { model }\end{array}$ & $\begin{array}{l}\text { Overall the } \\
\text { consultation model } \\
\text { uses language } \\
\text { clinicians might } \\
\text { experience as } \\
\text { unfamiliar, confusing, } \\
\text { and difficult to } \\
\text { understand, which } \\
\text { might 'alienate' } \\
\text { clinicians (stated) or } \\
\text { disengage them from } \\
\text { participation } \\
\text { (inferred). }\end{array}$ & U & $\mathrm{H}$ & ST & $\mathrm{F}$ & CS \\
\hline \multicolumn{10}{|c|}{ Complexity: refers to how straightforward (or not) it is to address an issue } \\
\hline \multicolumn{10}{|c|}{ U: User access to knowledge/experience problem } \\
\hline \multicolumn{10}{|c|}{ H: Hidden problem } \\
\hline \multicolumn{10}{|c|}{ ST: Sequence \& timing problem } \\
\hline \multicolumn{10}{|c|}{ F: Feedback problem } \\
\hline \multicolumn{10}{|c|}{ CS: Cognitive or social demands problem } \\
\hline
\end{tabular}


Table 4. Consultation Strategy Redesign Decisions

\section{Consultation Redesign}

Development of Troubleshooting Guide (guidelines, examples and tips) for consultants

\section{Usability issues}

*Focus on barriers detracts from case presentation

*Unprepared to identify solutions to barriers

*Digressions derail barrier problem solving and engagement

*Case presentations exceed time allotted

*Unfamiliar case update structure
Clearly defined call agenda, directions and expectations for call activities and participation

*Focus on barriers detracts from case presentation

*Unprepared to identify solutions to barriers

*Digressions derail barrier problem solving and engagement

*Case presentations exceed time allotted

Provision of examples (e.g., case presentation) via multiple formats (i.e., modeled in vivo by consultant, discussion board, handouts)
*Focus on barriers detracts from case presentation

*Unprepared to identify solutions to barriers

*Digressions derail barrier problem solving and engagement

*Unprepared to articulate updated monitoring targets

*Case presentations exceed time allotted

*Unfamiliar case update structure

*Difficulty articulating what's being measured
Opportunity to ask overflow questions/comments to continue via asynchronous discussion board with both consultant and call group
*Focus on barriers detracts from case 
*Digressions derail barrier problem solving and engagement

*Case presentations exceed time allotted

*Consultation call duration too brief

Consistent use of affirmation and positive feedback during call discussion, practice activities and discussion board use

*Focus on barriers detracts from case presentation

*Unprepared to identify solutions to barriers

*Discomfort with assessments in case presentations

Development of participant handbook including information on all available resources and how-tos on accessing and utilizing technology (discussion board, training resources, calls), etc.

${ }^{*}$ Case presentations exceed time allotted

*Unfamiliar case update structure

*No continued access to resources

*Unaware of available follow up supports

*Unfamiliar language in consultation model

Consultant screen-shares appropriate resources, materials or examples during call

*Distraction from multitasking online during calls

*Technological difficulties are disengaging

Research team available to troubleshoot any technological issues or needs during consultation calls

*Inadequate on-site technology

*Technological difficulties are disengaging

Additional technical training for consultants (e.g., learning dashboard, zoom videoconference, etc.)

*Inadequate on-site technology

*Distraction from multitasking online during calls 
*Technological

difficulties are

disengaging

Orientation for participants on training platform during first call (i.e., discussion board, additional resources)
*Unaware of available

follow up supports

*Technological

difficulties are

disengaging

Promotion of collaborative, safe environment to share via introductions, profile photos and video during calls

Participants given one of top choices (rank order) of their preferred time for consultation calls

Offered brief make-up sessions if scheduled group calls were missed (based on their availability)

Reduction of consultation call time from 1-1.5 hours to 50 minutes

Allowed continued access to the training modules

Development of supplemental MBC resources and reference materials (e.g., workflow tools, standardized assessments repository, MBC tip sheets, etc.)
*No continued access to resources

*Unaware of available follow up supports

*Confidentiality concerns when reporting results

*Regular calls incompatible with time/availability

*Duration misaligned with preferences

*Regular calls incompatible with time/availability

*Rapid assessment misaligned with available time

*Regular calls incompatible with time/availability

*Duration misaligned with preferences

*Focus on barriers detracts from case presentation

*No continued access to resources

*Discomfort with assessments in case presentations

*Unaware of available follow up supports

*Confusion over MBC terminology
Revised language (e.g., reduced jargon, increased readability, clear definitions, etc.) across all project materials 
*Unfamiliar language in consultation model

Broke down MBC process into manageable steps (sequence of practice activities followed by feedback) to better align with call timeline

*Unprepared to articulate updated monitoring targets

*Case presentations exceed time allotted

\section{Figures}

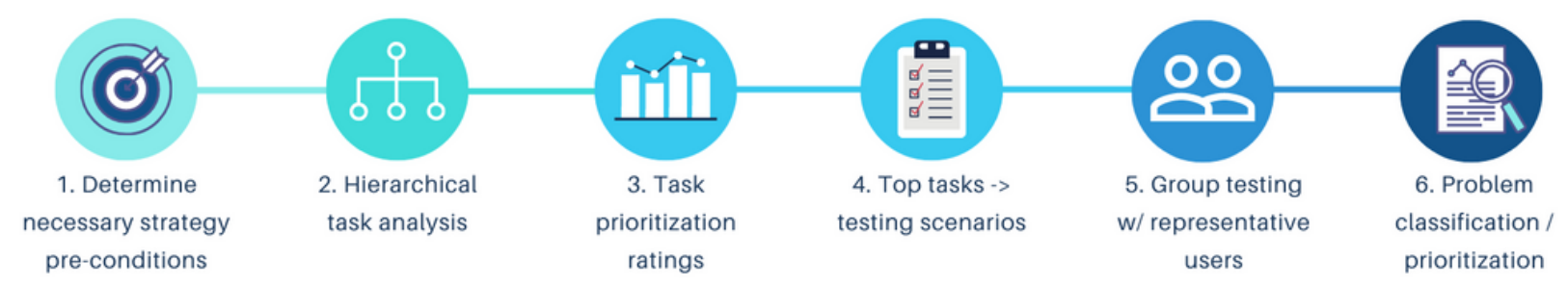

Figure 1

Overview of the Cognitive Walkthrough for Implementation Strategies (CWIS) Methodology. 


\section{Task 2-1}

Select a case with which you have used $M B C$ over multiple sessions and describe

the results of initial administration of the

standardized instruments you selected,

including: the student's scores, how the

scores relate to established norms, what

the student's response was to the results,

and the intervention goals you and the

student identified.

multiple students on your caseload.

Prior to the call, you are informed that

all trainees will need to give an additional case presentation, again

focused on the use of MBC practices

with one of your students.

Task 2-2

Based on the student's intervention goals, briefly describe (a) the rationale for

ongoing assessments for this case, (b)

how you have defined/operationalized

what a positive intervention response

would look like, and (c) your next steps for using MBC with the student.

Figure 2

Example CWIS Scenario and Subtasks. 


\begin{tabular}{|c|c|c|c|c|c|c|c|c|c|c|c|c|c|}
\hline \multirow{2}{*}{ Scenario } & \multirow{2}{*}{\multicolumn{2}{|c|}{ Task }} & \multicolumn{10}{|c|}{ Participang Ratings of Anticipated Task Success } & \multirow{2}{*}{$\begin{array}{c}\text { Very } \\
\text { confident } \\
\text { in success }\end{array}$} \\
\hline & & & 1 & 2 & 3 & 4 & 5 & 6 & 7 & 8 & 9 & 10 & \\
\hline \multirow{3}{*}{1} & \multirow{3}{*}{ 1-1 } & knowing what to do & & & & & & & & & & & $50 \%$ \\
\hline & & doing it & & & & & & & & & & & $30 \%$ \\
\hline & & learning you did it sucessfully & & & & & & & & & & & $30 \%$ \\
\hline \multirow{6}{*}{2} & \multirow{3}{*}{ 2-1 } & knowing whot to do & & & & & & & & & & & $40 \%$ \\
\hline & & doing it & & & & & & & & & & & $20 \%$ \\
\hline & & iearning you did it sucessfully & & & & & & & & & & & $40 \%$ \\
\hline & \multirow{3}{*}{$2-2$} & knowing what to do & & & & & & & & & & & $30 \%$ \\
\hline & & doing it & & & & & & & & & & & $10 \%$ \\
\hline & & iearning you did it sucessfully & & & & & & & & & & & $50 \%$ \\
\hline \multirow{9}{*}{3} & \multirow{3}{*}{ 3-1 } & knowing what to do & & & & & & & & & & & $90 \%$ \\
\hline & & doing it & & & & & & & & & & & $50 \%$ \\
\hline & & learning you did it sucessfully & & & & & & & & & & & $70 \%$ \\
\hline & \multirow{3}{*}{ 3-2 } & knowing what to do & & & & & & & & & & & $70 \%$ \\
\hline & & doing it & & & & & & & & & & & $60 \%$ \\
\hline & & learning you did it sucessfully & & & & & & & & & & & $70 \%$ \\
\hline & \multirow{3}{*}{$3-3$} & knowing what to do & & & & & & & & & & & $50 \%$ \\
\hline & & doing it & & & & & & & & & & & $30 \%$ \\
\hline & & iearning you did it sucessfully & & & & & & & & & & & $40 \%$ \\
\hline \multirow{3}{*}{4} & \multirow{3}{*}{ 4-1 } & knowing what to do & & & & & & & & & & & $40 \%$ \\
\hline & & doing it & & & & & & & & & & & $10 \%$ \\
\hline & & Iearning you did it sucessfully & & & & & & & & & & & $70 \%$ \\
\hline \multirow{6}{*}{5} & \multirow{3}{*}{ 5-1 } & knowing what to do & & & & & & & & & & & $60 \%$ \\
\hline & & doing it & & & & & & & & & & & $30 \%$ \\
\hline & & learning you did it sucessfully & & & & & & & & & & & $60 \%$ \\
\hline & \multirow{3}{*}{$5-2$} & knowing what to do & & & & & & & & & & & $70 \%$ \\
\hline & & doing it & & & & & & & & & & & $30 \%$ \\
\hline & & learning you did it sucessfully & & & & & & & & & & & $30 \%$ \\
\hline \multirow{6}{*}{6} & \multirow{3}{*}{$6-1$} & knowing whot to do & & & & & & & & & & & $80 \%$ \\
\hline & & doing it & & & & & & & & & & & $60 \%$ \\
\hline & & iearning you did it sucessfully & & & & & & & & & & & $50 \%$ \\
\hline & \multirow{3}{*}{$6-2$} & knowing what to do & & & & & & & & & & & $80 \%$ \\
\hline & & doing it & & & & & & & & & & & $60 \%$ \\
\hline & & iearning you did it sucessfully & & & & & & & & & & & $80 \%$ \\
\hline & & Rating Scale & & & & bably & No, & $\begin{array}{l}\text { bably } \\
t\end{array}$ & & & & & \\
\hline
\end{tabular}

\section{Figure 3}

CWIS Task Success Ratings for all Subtasks and Participants.

\section{Supplementary Files}

This is a list of supplementary files associated with this preprint. Click to download. 
- CWISAdditionalFile1FullScenarioTaskList.pdf

- CWISAdditionalFile2TaskRatingSheet4.17.18.pdf

- CWISAdditionalFile3ISUS.pdf 